\title{
Estratégias de Letramento voltadas à intervenção fonoaudiológica em pessoas com Síndrome de Down
}

Strategies for Speech Therapy for Speech-Language Pathology in People with Down's Syndrome

Estrategias de lectura orientadas a la intervención fonoaudiológica en personas con Síndrome de Down

\section{* Isabelle Cahino Delgado}

Professora da Universidade Federal da Paraíba, João Pessoa, Paraíba, Brasil. fgaisabelle@hotmail.com

\section{** Talita Maria Monteiro Farias Barbosa}

Mestre pela Universidade Federal da Paraíba, João Pessoa, Paraíba, Brasil. talita_farias@hotmail.com.br

\section{*** Bruna Samyres Oliveira de Macêdo,} Graduada pela Universidade Federal da Paraíba, João Pessoa, Paraíba, Brasil. bsoliveiram@gmail.com

\section{**** Cynderella Karla Moraes de Lima}

Mestranda pela Universidade Federal da Paraíba, João Pessoa, Paraíba, Brasil. cindy.karla@hotmail.com

\section{***** Mariane Sousa Régis}

Graduada pela Universidade Federal da Paraíba, João Pessoa, Paraíba, Brasil. mmariregis@gmail.com

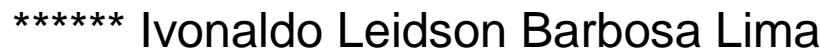

Doutorando pela Universidade Federal da Paraíba, João Pessoa, Paraíba, Brasil. ivonaldoleidson@gmail.com

\section{****** Giorvan Ânderson dos Santos Alves}

Professor da Universidade Federal da Paraíba, João Pessoa, Paraíba, Brasil. anderson_ufpb@yahoo.com.br

Recebido: 14 de janeiro de 2018

Aprovado: 23 de janeiro de 2019

\section{RESUMO}

Esse estudo objetivou caracterizar e discutir as estratégias de letramento utilizadas na intervenção fonoaudiológica em sujeitos com síndrome de Down. Para isso, foram analisados os prontuários de 29 pessoas, de ambos os sexos, atendidos em um projeto de extensão universitária, com idades entre dois e trinta e um anos. A análise dos dados observou as 
práticas de letramento utilizadas com os indivíduos, seguido da categorização em dois grupos de acordo com os objetivos da intervenção. O primeiro grupo focava o desenvolvimento das estratégias com foco na modalidade oral da língua, como: leitura de livros infantis; atividades de psicomotricidade associando à linguagem oral; leitura de histórias e recontagem; uso de músicas infantis, explorando o conteúdo da mesma. Já o objetivo do segundo grupo era o de desenvolver a linguagem escrita, fazendo com que o indivíduo entendesse e utilizasse a escrita em sua funcionalidade, como: leitura de histórias que sejam do interesse do sujeito, produção de diversos gêneros textuais, jogos que explorem a consciência fonológica, uso dos gêneros digitais. Observou-se que as estratégias de letramento encontradas puderam contribuir para o desenvolvimento linguístico, educacional e social da pessoa com síndrome de Down, as mesmas buscam envolver a linguagem nas práticas sociais. As estratégias são benéficas para o trabalho do fonoaudiológico, assim como, para outros profissionais que lidam com a população estudada.

Palavras-chave: Letramento; Síndrome de Down; Linguagem.

\section{ABSTRACT}

This study aimed to characterize and discuss the literacy strategies used in speech therapy intervention in subjects with Down syndrome. For that, the medical records of 29 people, of both sexes, attended in a university extension project, between the ages of two and thirty-one, were analyzed. The analysis of the data observed the literacy practices used with the individuals, followed by the categorization into two groups according to the objectives of the intervention. The first group focused on the development of strategies focused on oral language, such as reading children's books; Psychomotricity activities associated with oral language; reading stories and recounting; use of children's music, exploring the content of it. The aim of the second group was to develop written language, making the individual understand and use writing in its functionality, such as: reading stories that are of interest to the subject, producing various textual genres, games that explore phonological awareness, use of digital genres. It was observed that the strategies of literacy found could contribute to the linguistic, educational and social development of the person with Down syndrome, they seek to involve language in social practices. The strategies are beneficial for speech therapy work, as well as for other professionals who deal with the studied population.

Keywords: Literature; Down's syndrome; Language.

\section{RESUMEN}

Este estudio objetivó caracterizar y discutir las estrategias de letramento utilizadas en la intervención fonoaudiológica en sujetos con síndrome de Down. Para ello, se analizaron los prontuarios de 29 personas, de ambos sexos, atendidos en un proyecto de extensión universitaria, con edades entre dos y treinta y un años. El análisis de los datos observó las prácticas de letramento utilizadas con los individuos, seguido de la categorización en dos grupos de acuerdo con los objetivos de la intervención. El primer grupo se centraba en el desarrollo de las estrategias con foco en la modalidad oral de la lengua, como: lectura de libros infantiles; actividades de psicomotricidad asociando al lenguaje oral; lectura de historias y recuento; el uso de música infantil, explorando el contenido de la misma. El objetivo del 
segundo grupo era el de desarrollar el lenguaje escrito, haciendo que el individuo entendiera y utilizara la escritura en su funcionalidad, como: lectura de historias que sean del interés del sujeto, producción de diversos géneros textuales, juegos que explotan la conciencia fonológica, el uso de los géneros digitales. Se observó que las estrategias de letramento encontradas pudieron contribuir al desarrollo lingüístico, educativo y social de la persona con síndrome de Down, las mismas buscan involucrar el lenguaje en las prácticas sociales. Las estrategias son beneficiosas para el trabajo del fonoaudiológico, así como para otros profesionales que se ocupan de la población estudiada.

Palabras clave: alfabetización; Sindrome de Down; Idioma.

\section{Introdução}

A síndrome de Down (SD) é caracterizada por ser uma alteração na divisão típica dos cromossomos, resultando na triplicação do cromossomo 21, que pode ocorrer de três modos distintos (BISSOTO, 2005). A maioria dos casos, cerca de $95 \%$, ocorre por trissomia do cromossosmo 21 por não-disjunção que é a presença de três cromossomos $21 \mathrm{em}$ todas as células, pois durante a divisão celular meiótica no período embrionário, não ocorre separação dos cromossomos 21 . Cerca de 3 a $4 \%$ dos casos ocorre por translocação, no qual todo o cromossomo 21 extra ou parte dele está ligado a outro cromossomo, geralmente o 14. E em sua forma mais rara, cerca de $1 \%$, ocorre por mosaicismo que é considerada como o resultado de um erro nas primeiras divisões celulares, porém nem todas as células contêm o cromossomo extra, e a criança pode ter menos características físicas comuns da SD e menor comprometimento intelectual (KOZMA, 2007).

As principais características clínicas da SD são: comprometimento intelectual; hipotonia muscular; fissura palpebral oblíqua; hiperextensão articular; baixa estatura; mãos largas e dedos curtos; cardiopatias congênitas; perdas auditivas; otites médias com efusão ou crônicas, entre outras. Esses aspectos clínicos e limitações decorrentes dos mesmos acabam por interferir no desenvolvimento global da criança com a síndrome e alguns deles apresentam implicação direta no desenvolvimento da linguagem nessas crianças (LIMONGI, 2004). Logo após o diagnóstico, é importante que a criança com SD já inicie um acompanhamento com uma equipe de profissionais habilitados, a fim de promover a estimulação precoce, potencializando assim, seu desenvolvimento.

A linguagem é uma das áreas que se apresenta mais comprometida em indivíduos com Síndrome de Down, quando comparada ao desenvolvimento de outras áreas, como a cognitiva, social e motora. As crianças com a síndrome apresentam déficits em alguns mecanismos que auxiliam no desenvolvimento da linguagem oral e escrita, como problemas 
http://dx.doi.org/10.5902/1984686X24631

para obter rapidamente a informação léxica (gama de palavras que uma língua contém), déficits quanto á ordem fonético-fonológica, memória auditiva e espaço-temporal, sintaxe, raciocínio lógico, morfologia, pragmática, semântica e consciência fonológica (FEITOSA; TRISTÃO, 1998; RANGEL; RIBAS, 2011).

Diante das dificuldades de linguagem apresentadas pelos sujeitos com SD, é de extrema importância a estimulação precoce no que se refere à linguagem oral e escrita, pois contribui para a diminuição dos déficits, evitando assim maiores atrasos no seu desenvolvimento cognitivo e social, além da promoção da neuroplasticidade cerebral.

A palavra letramento é originada da palavra inglesa literacy, a qual diz respeito ao estado ou condição que assume aquele que aprende a ler e escrever. Este conceito traz a ideia que adquirir a tecnologia do ler e escrever e se evolver nas práticas de leitura e de escrita traz consequências sobre o indivíduo. Alterando os aspectos sociais, cognitivos, políticos, culturais, psíquicos, linguísticos e econômicos (SOARES, 2009).

O termo letramento no Brasil aparece quase sempre junto ao termo alfabetização, isso se dá devido ao despertar para importância e necessidade do uso da leitura e escrita nas diferentes demandas, tem sua origem vinculada à aprendizagem inicial da escrita (SOARES, 2004). Apesar de ser inegável a associação entre os dois termos é importante ressaltar as diferenças entre a alfabetização e letramento. Segundo Soares (2009), a pessoa alfabetizada é aquela que sabe ler e escrever, ou seja, aprendeu a codificar e decodificar a língua escrita, porém não faz uso da mesma. Já a pessoa letrada é aquela que faz uso competente e frequente da leitura e da escrita, envolve-se nas práticas sociais de leitura e escrita e tem a escrita como própria. O sujeito letrado, então, não se limita apenas a saber ler e escrever um tipo de escrita particular, mas em aplicar esse conhecimento para propósitos específicos em contextos sociais específicos. Assim, podemos afirmar que não existe um letramento, mas letramentos (TERRA, 2013).

O letramento assume um papel em várias atividades dentro da sociedade. Essas atividades podem envolver: uma interação face-a-face numa entrevista; pessoas que interagem oralmente com a mediação da leitura, como discutir oralmente a história de um livro e uma interação à distância, como por uma carta. Assim mais uma vez percebemos que as práticas envolvem as modalidades oral e escrita, algumas delas mais voltadas para oralidade, outras para escrita.

As modalidades oral e escrita de uso da língua são vistas como funções complementares nas práticas letradas de comunicação. De forma que as duas modalidades 
http://dx.doi.org/10.5902/1984686X24631

possam mediar uma mesma atividade de comunicação social, o que invalida a ideia da dicotomia entre oralidade e escrita (TERRA, 2013). Por exemplo, antes ou depois de fazer uma leitura, fazemos perguntas sobre o texto e assunto, através da fala. A criança, por exemplo, sem ser alfabetizada, finge que lê um livro. Se ela vive em um ambiente literário, vai com o dedo na linha, e faz as entonações de narração da leitura, até com estilo.

Assim um novo conceito que vem surgindo é o de letramento oral, o qual se refere a um conjunto de práticas que mesmo materializadas na modalidade oral da língua, reflete movimentos que dizem respeito ao funcionamento de textos escritos. O letramento oral também tem o papel de subsidiar o letramento escrito. Um exemplo disso é na escola, onde as crianças conversam, expõem, debatem, por meio dos gêneros orais e cruzam com gêneros escritos, como listas, livros (MEDEIROS, 2012).

A Fonoaudiologia é uma das ciências que se beneficia do uso das práticas de letramento no âmbito da linguagem. A partir do exposto, vemos que é possível fazer seu uso para manejar trabalhos com a linguagem na prática, seja no suporte às trajetórias desejáveis de aquisição da linguagem, a fim de maximizar seu uso, seja na intervenção de transtornos que podem acometê-la (RIBEIRO; SOUZA, 2012). Nesse contexto, o intuito é de que a linguagem, seja escrita ou oral, corresponda às demandas socioculturais diversas, e não tenha fim em si mesmo. As ações que objetivam promover o letramento devem ser previamente contextualizadas, checando interesses e conhecimento prévio sobre as atividades, para que seja gerada maior mobilização obtendo-se, assim, melhores resultados (BRITO et al, 2010).

Incluir o sujeito com síndrome de Down no processo de letramento é fundamental, visto que a leitura e a escrita estão presentes em todo lugar fazendo parte da vida e do cotidiano da sociedade letrada, e tem um papel importante para a inclusão social (FEISTAUER, 2014). Sendo assim, a possibilidade de acesso a práticas de letramento na SD, é um fator positivo para a sua inclusão nos diversos grupos sociais e consequente diminuição do preconceito e discriminação que esses indivíduos sofrem ao longo dos anos (COENGA, 2008).

Vale ressaltar, que não basta apenas inserir o sujeito em práticas de letramentos, é necessário pensar e fazer escolhas adequadas quanto ao uso das estratégias, para que alcancem a realidade e necessidade específica dos sujeitos. Nesse sentido, este trabalho objetivou caracterizar e discutir as estratégias de letramento utilizadas na intervenção fonoaudiológica em sujeitos com síndrome de Down. 


\section{Método}

Esta é uma pesquisa documental de caráter transversal (GIL, 2002), avaliada e aprovada pelo Comitê de Ética em Pesquisa com seres humanos da instituição de origem, sob o parecer de $n^{\circ}$ 1.302.829. Ela foi desenvolvida a partir do projeto "Letramento em Pauta: Intervenção Fonoaudiológica em Sujeitos com Síndrome de Down”, vinculado a uma Instituição de Ensino Superior da Paraíba.

Semanalmente, os sujeitos participantes da pesquisa foram submetidos a atendimentos na clínica-escola da instituição, os quais foram mediados por duas extensionistas do projeto que recebiam supervisão de dois fonoaudiólogos. Cada atendimento durava em média 40 minutos.

Neste estudo, foi realizada uma análise documental a partir dos prontuários de 29 pacientes que estavam sendo assistidos pelo projeto durante o ano de 2015, participando assiduamente das atividades. Dos 29 indivíduos, 16 eram do sexo masculino e 13 do sexo feminino, e estavam na faixa etária entre dois a 31 anos de idade.

A coleta dos dados foi realizada por meio dos registros e documentos dos prontuários, como relatórios, planejamentos terapêuticos e evolução dos pacientes vinculados ao projeto de extensão. A partir desses, foram observadas as estratégias de letramento utilizadas, as quais podem ser voltadas tanto para a oralidade como para escrita, a depender das necessidades e especificidades dos indivíduos. Partindo desse pressuposto, os sujeitos foram divididos em dois grupos.

Grupo 01 - composto por 20 sujeitos, sendo 12 do sexo masculino e oito do sexo feminino, com idade entre dois e 24 anos; todos submetidos a estratégias de letramento com foco na linguagem oral;

Grupo 02 - composto por nove sujeitos, sendo quatro do sexo masculino e cinco do sexo feminino, com idade entre dez e 31 anos; todos submetidos a estratégias de letramento com foco na linguagem escrita.

O critério de divisão dos grupos seguiu o foco principal da intervenção utilizada pelas extensionistas. O Grupo 01 caracteriza-se por sujeitos que estão em processo de desenvolvimento ou aprimoramento da linguagem oral e não adquiriram ainda o código 
http://dx.doi.org/10.5902/1984686X24631

escrito. No Grupo 02 , os sujeitos já eram alfabetizados ou encontram-se em processo de alfabetização.

A análise dos dados pode ser dividida em três momentos (LIMA et al, 2015): 1) Seleção e compilação das estratégias utilizadas em cada grupo; 2) Organização dos dados em categorias de análise; 3) Interpretação dos dados, a partir de análise qualitativa do conteúdo, e criação de quadros para facilitar a exposição das informações.

\section{Resultados}

A partir dos dados obtidos e da análise dos grupos de estratégias, pôde-se observar que o objetivo do Grupo 01 foi desenvolver a linguagem oral, com foco no letramento, levando o sujeito a aperfeiçoar suas habilidades comunicativas no meio social, visando aperfeiçoar as habilidades comunicativas nesse âmbito, desenvolvendo uma melhor prática social, fazendo com que o indivíduo participasse de forma mais significativa de eventos de letramento, por exemplo: na escola, no dia a dia, com a família, na vida social e em atividades intelectuais e laborais, aumentando sua interação social.

Além disso, proporcionava aos sujeitos recursos cognitivos para a aprendizagem de novas palavras e enunciados, através de atividades que possibilitassem a aquisição da oralidade e, posteriormente, o aprendizado da escrita (Quadro 1).

Quadro 1: Estratégias desenvolvidas com o Grupo 01

$\checkmark \quad$ Leitura compartilhada de livros infantis;

$\checkmark$ Atividades que simulem ações diárias (comer, vestir) do sujeito com uso de brinquedos;

$\checkmark$ Atividades de psicomotricidade associando à linguagem oral, remetendo sempre a realidade da criança (colagem dos elementos da praia, supermercado, de higiene pessoal, fazendo uso de diferentes texturas);

$\checkmark$ Assistir desenhos pela metade e estimulá-lo a continuar a história;

$\checkmark$ Leitura de histórias e recontagem pelo sujeito ao término, e incentivá-lo a responder perguntas sobre fatos relevantes na história;

$\checkmark$ Histórias e jogos que envolvam sentimentos associando a expressões faciais e corporais (alegria, medo, tristeza);

$\checkmark$ Contar histórias com uso de objetos que componham o cenário da mesma;

$\checkmark$ Jogos de sequência lógica, que envolvam noções espaciais e temporais, como ordenar as imagens referentes a uma ação, e ao mesmo tempo descrevê-las;

$\checkmark$ Jogos de raciocínio lógico e matemático, como explorar a contagem de ingredientes de uma receita, contar os animais da história;

$\checkmark$ Cantigas de roda em grupos, músicas infantis que envolvam movimentos corporais, explorando o conteúdo da mesma;

$\checkmark \quad$ Uso de livros sem palavras, apenas com imagens para que o sujeito crie a sua história. 
http://dx.doi.org/10.5902/1984686X24631

Já o objetivo do Grupo 02 foi desenvolver a linguagem escrita, despertando no indivíduo com síndrome de Down o gosto pela leitura e pela escrita, dando-lhes também melhores condições de decodificação e compreensão da leitura, além de uma escrita mais organizada e com menos erros, fazendo com que o indivíduo entenda e a utilize em sua funcionalidade, através da familiarização com essa linguagem em situações diversas. Consequentemente, torna-se mais confiante quanto a sua capacidade de se comunicar e de expressar suas próprias ideias, além de usar com mais propriedade o repertório linguístico (Quadro 2).

Quadro 2: Estratégias desenvolvidas com o Grupo 02

\section{ESTRATÉGIAS DE LETRAMENTO COM FOCO NA LINGUAGEM ESCRITA}

$\checkmark \quad$ Leitura compartilhada de histórias que sejam do interesse do sujeito, como histórias em quadrinho, textos de revistas, poesia, narrativa ou contos;

$\checkmark$ Interpretação de texto a partir de perguntas sobre o mesmo;

$\checkmark$ Escrever um resumo ou parte preferida de uma história;

$\checkmark$ Produção de diversos gêneros textuais como: notícia, carta, bilhetes, listas de compras e receitas sempre envolvendo a realidade e as relações do sujeito;

$\checkmark$ Exploração e confecção de cartazes, convites e anúncios;

$\checkmark$ Leitura de histórias pela metade, estimulando o sujeito a criar e escrever um fim para a mesma;

$\checkmark$ Jogos de sequência lógica como ordenar imagens referente às cenas da história (que fora lida antes), atentando para a ordem temporal, os personagens e lugares; ou ordenar imagens alusivas a ações cotidianas;

$\checkmark$ Simular, no ambiente de terapia, situações habituais como ida ao shopping, supermercado, livraria explorando a comunicação, a interação e a relação lógico-matemática (quantos itens serão comprados, quanto custa). A atividade pode contar com a produção de uma lista de compras previamente estabelecida, por exemplo;

$\checkmark$ Relatar através da produção de um texto e desenhos, ações e tarefas diárias, um fim de semana ou passeio;

$\checkmark$ Atividades com músicas de interesse do sujeito para que o mesmo interprete a letra e escreva trechos preferidos;

$\checkmark$ Criação de rimas;

$\checkmark$ Utilização do computador para fazer buscas na internet, envio de e-mails e uso de programas, geralmente de escrita e pintura;

$\checkmark$ Jogo de perguntas e respostas sobre conhecimentos gerais realizados em dupla;

$\checkmark$ Jogos que explorem a consciência fonológica e jogos que fixem a ortografia correta das palavras, como palavras cruzadas, caça-palavras, forca, stop, soletrando.

\section{Discussão}

Apesar de o presente trabalho separar as estratégias em modalidade oral e escrita, trata-se basicamente de um critério metodológico, já que a relação entre linguagem oral e escrita deve ser de continuidade e ambas são interdependentes.

Existe uma escassez na literatura nacional referente ao uso das práticas voltadas ao letramento no trabalho fonoaudiológico clínico com pessoas com SD. A maioria das pesquisas como as de Brito et al (2010), de Schneider et al (2010), de Medeiros (2012) e de Sato et al (2012), tratam do uso das estratégias letramento no âmbito escolar, o que é 
http://dx.doi.org/10.5902/1984686X24631

esperado, já que trata-se de um termo bastante ligado a escolarização. Sendo necessário mais estudos nas áreas citadas a fim de oferecer possíveis benefícios a população com SD.

Quanto à idade cronológica dos participantes do estudo, essa não foi determinante para decidir se os mesmos enquadram-se no grupo um ou grupo dois do estudo. Sabendo que em muitos dos sujeitos do presente estudo a idade cronológica não corresponde com o desenvolvimento esperado. O que revela a importância de um trabalho terapêutico singular, de acordo com as necessidades individuais, pois cada criança irá apresentar dificuldades linguísticas particulares que despertam a necessidade de uma intervenção categorizada e pautada em fatores como: a cognição do indivíduo, nível linguístico, habilidades comunicativas, o processo de alfabetização, assim como a dinâmica familiar e social em que o mesmo está inserido.

No primeiro grupo, podemos observar que a maioria das estratégias utilizadas fazem uso dos gêneros orais, jogos de linguagem como também utilizam materiais escritos que subsidiam para letramento na linguagem escrita. De acordo com Medeiros (2012), é a partir dos jogos de linguagem, entendendo esses como relação/funcionamento que configura a base da aprendizagem para os gêneros discursivos da língua, possibilitando por parte da criança e jovens a inserção no mundo letrado.

De acordo com as estratégias encontradas nesse artigo em relação à modalidade oral, é importante a presença do trabalho fonoaudiológico voltado ao letramento com a pessoa com SD, pois elas possibilitam um desenvolvimento tanto nos níveis linguísticos, como cognitivos e sociais. Um exemplo é o trabalho com a leitura compartilhada de livros infantis, leitura de histórias e recontagem pela pessoa, e incentivo a responder perguntas sobre fatos relevantes na história que intensificam os aspectos relacionados à cognição e à socialização, desenvolvendo a capacidade de resolução de problemas, expansão do seu conhecimento de mundo, aprimoramento nas habilidades de expressão e compreensão da linguagem, além de desenvolver a memória, reestruturar conceitos e colaborar no desenvolvimento da escrita.

O trabalho com foco na modalidade oral faz com que o indivíduo com SD, compreenda que as palavras contêm significados e que elas devem ser empregadas de acordo com o contexto em que se insere, pensando no seu uso correto, desenvolvendo as práticas sociais de leitura e posteriormente da escrita.

Contar histórias com uso de recursos diversos como objetos e brinquedos que representem o cenário ou personagens da história, mudar a entonação da voz, utilizar-se de expressões faciais e corporais; contar as histórias pela metade; fazer perguntas sobre a 
http://dx.doi.org/10.5902/1984686X24631

mesma; podem despertar a criatividade dos envolvidos, auxiliar no desenvolvimento da função simbólica, aprimorar os aspectos cognitivos necessários para o avanço no desenvolvimento da linguagem, e ampliar as noções de que o uso da leitura e da escrita está muito mais além dos livros e atividades escolares. O uso de jogos de linguagem, de consciência fonológica, as cruzadinhas, a criação de rimas, estimulam os indivíduos com SD a aprenderem de forma lúdica algumas regras gramaticais simples para a formação do discurso oral e escrito. A estimulação ajuda a diminuir os déficits apresentado por esses indivíduos, mas é importante considerar os fatores intrínsecos ao realizá-la, para que não seja exigido mais do que ele seja capaz (ALVES, DELGADO e VASCONCELOS, 2008).

As estratégias realizadas no primeiro grupo baseiam-se no fato dos participantes estarem em processo de aquisição da linguagem e de apresentarem dificuldades na oralidade como: dificuldades em se comunicar, incapacidade de contar uma pequena história, dificuldade com conceitos abstratos e função simbólica, entre outras. Mesmo não sabendo ler nem escrever, inseridos nas práticas de letramento, já começam a entender o uso e a função da leitura e da escrita. Prova disso é que a criança pode contar histórias utilizando características da escrita como: introdução, desenvolvimento e conclusão, sequência lógica (FEISTAUER, 2014), folhear livros contando a história com base nas ilustrações, compreender um anuncio de supermercado pelas gravuras e disposição das letras e números no folheto, entre outras. Assim, compreendendo que a criança com SD apresenta um desenvolvimento linguístico mais atrasado em relação ao de crianças com desenvolvimento típico, é fundamental que ela tenha experiências variadas e concretas nessa fase de aquisição e desenvolvimento da linguagem oral, o que auxilia a minimizar as dificuldades que eles apresentam e subsidiar o desenvolvimento da leitura e da escrita (LIMA, DELGADO e CAVALCANTE, 2017).

Da mesma maneira, a apropriação da linguagem escrita influencia o desempenho do discurso oral do sujeito (MEDEIROS, 2012). Portanto, mesmo que o foco das estratégias em um grupo seja voltado para a modalidade oral, isso não impede que ocorra um trabalho em conjunto com a linguagem escrita; da mesma forma que no trabalho com a modalidade escrita, a linguagem oral também é diretamente beneficiada.

Nas pessoas com síndrome de Down, a aquisição da linguagem escrita varia de indivíduo para indivíduo, e depende do grau de deficiência cognitiva que cada um deles apresenta (FEISTAUER, 2014). Outras dificuldades observadas nessa população são: déficits na função simbólica, nos processos de memória, nos processadores da linguagem e 
http://dx.doi.org/10.5902/1984686X24631

de atenção; que justificam as dificuldades e o atraso no desenvolvimento da linguagem escrita (ALVES, DELGADO e VASCONCELOS, 2008).

De acordo com Feistauer (2014), nos anos escolares iniciais dos indivíduos com SD as limitações mais visíveis são as de processamento auditivo e de memória, prejudicando o desenvolvimento da linguagem e da comunicação. Pessoas com SD, no final da infância e durante a adolescência, podem apresentar alterações morfossintáticas e lexicais, como: organização gramatical pobre; dificuldades no emprego de tempo verbais e gênero; e dificuldades nas relações entre sujeito-verbo e substantivos-adjetivos (LIMA, DELGADO e CAVALCANTE, 2017). Sendo a linguagem dos adolescentes marcada por enunciados curtos, estabelecidos no presente com frases simples, caracterizando um discurso simples (BARRIO, 1997).

Diante das dificuldades que as pessoas com síndrome de Down possuem frente à linguagem escrita, a inserção precoce nas práticas de letramento, promovem autonomia e integração destas pessoas na sociedade.

No segundo grupo, as terapeutas utilizam diversos gêneros textuais e abordam diferentes materiais escritos, como cartas, músicas, notícias, livros. Tais estratégias encontradas corroboram com os trabalhos dos autores Soares (2009) e Kleiman (2005), que descrevem as estratégias de letramento como uso de numerosos materiais escritos que circulam em um determinado meio constituindo a prática social da leitura e escrita. Também foi possível observar a realização de ações com os gêneros digitais que se refere às práticas de criar e administrar páginas na web, textos, individualmente ou coletivamente, encorajando a comunicação e o diálogo. Oportunizando aos alunos a realização das práticas de leitura e escrita (ARAÚJO, 2007; SOARES, 2004).

O trabalho de Ribeiro e Souza (2012) foi realizado com escolares entre cinco e seis anos e demonstrou que eles apresentam familiaridade com as práticas de letramento. E Brito et al (2010), no seu estudo percebeu mudanças qualitativas no letramento de alunos submetidos a um programa de sete semanas de estimulação de letramento. Assim, tanto a familiaridade dos sujeitos com as práticas que estão presentes no dia a dia, como a melhoria significativa no letramento após a realização das práticas, fornecem respaldo para utilização das estratégias de letramento nas ações do trabalho fonoaudiológico, inclusive com aqueles que apresentem dificuldades e/ou distúrbios de escrita.

A estratégia de letramento com as atividades de leitura e/ou produção de diversos gêneros textuais durantes as terapias fonoaudiológicas auxiliam no desenvolvimento 
http://dx.doi.org/10.5902/1984686X24631

cognitivo e ampliam os níveis de letramento das pessoas com SD, pois de acordo com Feistauer (2014) o letramento é voltado para as práticas sociais e a utilização dos mais diversos tipos de textos remete o uso e função da leitura e da escrita no cotidiano, ou seja, a prática fonoaudiológica seria mais contextualizada as necessidades diárias dos pacientes, ao desenvolvimento comunicativo essencial as suas atividades, mediadas pela linguagem escrita.

Em um estudo realizado por Signor (2012) com adolescentes com queixas de linguagem escrita, verificou-se, durante a avaliação, que a maior barreira apresentada desse público era a rejeição às práticas de leitura e escrita. Nas terapias, então, foram usados vários gêneros textuais, e os sujeitos foram imersos em uma série de práticas sociais de leitura e escrita o que proporcionou uma vivência necessária para domínio do gênero usado e conhecimento das propriedades essenciais do mesmo. Após a intervenção, os sujeitos conseguiram produzir textos adequados ao gênero em questão, levando a acreditar que a proposta pautada no contato efetivo com o gênero, por meio de um contexto significativo do uso da língua, proporciona aos sujeitos competências necessárias para interação nas práticas (SIGNOR, 2012).

Feistauer (2014) afirma que uma grande variedade de gêneros textuais exercita a habilidade cognitiva do sujeito e amplia sua capacidade de expressão linguística e que o uso dos gêneros aumenta o nível de letramento. E que esse contato deve ocorrer desde cedo, mesmo ainda não dominando a decodificação do sistema linguístico. Trabalhar com os gêneros, significa reconhecer a variedade de textos que circulam na sociedade, o que permite que os sujeitos tenham uma participação social mais efetiva e ampla.

Sabe-se ainda que as crianças com SD aprendem melhor com estímulos multissensoriais, assim quanto mais imagens, cores e materiais contextualizados com sua realidade mais interesse o sujeito terá em participar das atividades propostas. A variedade e a riqueza das práticas de letramento irão ajudar os sujeitos a conquistar níveis de letramento cada vez mais elevados (FEISTAUER, 2014).

A utilização de diversos estímulos multissensoriais, como citado anteriormente, durante as terapias constitui um aspecto positivo diante das dificuldades desses indivíduos, pois a memória visual dá apoio à memória auditiva de curto prazo, promovendo um maior nível de desenvolvimento e aprendizagem a esses sujeitos. (ALVES; DELGADO e VASCONCELOS 2008; FEISTAUER, 2014). 
http://dx.doi.org/10.5902/1984686X24631

As estratégias que envolvam simulação de ações e situações vividas na realidade pelos indivíduos, e leituras de histórias contextualizadas são de extrema importância para a ampliação do letramento nesses indivíduos. Essas atividades com situações existenciais, elementos da natureza e cultura amplia e valoriza os vínculos desses sujeitos com a realidade na qual estão inseridos (BRASIL, 2012).

A pessoa com SD, muitas vezes, vive um histórico de frustração na sua relação com a linguagem seja oral, ou escrita. Muitos sofrem no seu meio social devido aos déficits na habilidade comunicativa, além do fracasso escolar que também é bastante recorrente, no qual o aluno com SD vai para escola apenas para se relacionar socialmente, não tendo o apoio necessário para apropriação da linguagem escrita ou para passar por um processo dos conteúdos escolares satisfatório. Quando o sujeito percebe suas possibilidades, começa a ter uma relação diferente com a linguagem, uma relação que o torna protagonista e responsável por suas práticas e o torna ativo no processo de interação mediada pela linguagem escrita, e é essa relação que as estratégias de letramento pretendem despertar no sujeito com síndrome de Down.

O letramento nas modalidades oral e escrita potencializa a formação social desses indivíduos. De modo que, possibilita a inclusão dos sujeitos com SD em qualquer situação cotidiana que faça uso da língua, fornece aperfeiçoamento para os elementos necessários para construção do seu conhecimento, como também atua no desenvolvimento cognitivo, que na grande maioria deles é atrasado.

É importante lembrar que todo o processo de desenvolvimento de linguagem e uso da mesma, aqui discutido, sem o apoio da família e da escola seria pouco possível obter sucesso por parte dos sujeitos com SD. Justifica-se o exercício fundamental da escola junto à família e aos terapeutas, pois ela auxilia na formação desses sujeitos como leitores que relacionam o que leem e escrevem com o que veem, com o que sentem, com o que vivem, enfim, que construam significados sociais, históricos e políticos na leitura do texto a que se dedicam (FEISTAUER, 2014).

A interação entre sujeitos, mais e menos experientes, tanto no uso da modalidade oral quanto no da escrita é parte essencial para desenvolver habilidades sociais mais efetivas. Demonstrando a importância do papel da família junto à intervenção terapêutica. É função da família dar continuidade ao trabalho desenvolvido, pois as práticas devem se expandir para fora do ambiente clínico, ou seja, devem acontecer e permear o dia a dia do sujeito, tornando, de fato, o letramento efetivo. É preciso oportunizar ao sujeito estar inserido nas 
http://dx.doi.org/10.5902/1984686X24631

práticas sociais, possibilitando que frequente variados ambientes e realize, como ser independente, diversas atividades.

\section{Considerações Finais}

A síndrome de Down é uma condição genética que geralmente apresenta limitações cognitivas e linguísticas. Sendo assim, sabemos que os sujeitos com a síndrome necessitam de uma atenção terapêutica que forneça ações que contribuam para o seu desenvolvimento através de técnicas apropriadas. Partindo desse pressuposto, concluímos que as estratégias de letramento anteriormente propostas podem contribuir de forma expressiva para 0 desenvolvimento linguístico, educacional e social da pessoa com SD. Elas não só possibilitam uma melhora nos déficits cognitivos ou linguísticos apresentados, mas também fornecem uma maior competência e autonomia para realização de atividades linguísticas em diversos contextos sociais.

As principais estratégias encontradas no grupo com foco na linguagem oral referem-se à utilização dos gêneros orais, através dos jogos de linguagem, historinhas infantis e atividades que estimulem a função simbólica. Tais estratégias trazem benefícios tanto no desenvolvimento da linguagem oral do indivíduo com síndrome de Down, no que se refere a comunicar seus desejos e sensações oralmente e utilizar da linguagem como meio de inserção social, como também despertar para as habilidades necessárias para o desenvolvimento da escrita como: o conhecimento das letras, aptidão na linguagem oral, atenção e memória.

As estratégias encontradas com foco na escrita referem-se principalmente ao uso dos gêneros textuais, através de atividades que os envolvam, seja por meio de cartas, listas, narrativas, textos, entre outros. Tais práticas trazem benefícios para aprendizagem da língua escrita, possibilitando ao sujeito com síndrome de Down ganhos escolares, considerando a alfabetização e a relação com a língua, como também pessoais e sociais, por permitir ao sujeito compreender e participar de uma sociedade que usa efetivamente a língua escrita na maioria de seus contextos. Além desses, a aprendizagem da leitura e escrita também aperfeiçoam a expressão oral.

\section{Referências}

ALVES. G. A. S; DELGADO. I. C; VASCONCELOS. M. L. O desenvolvimento da linguagem escrita em crianças com síndrome de Down. Revista Prolíngua, João Pessoa, v.1, n.1, p. 47$55,2008$. 
http://dx.doi.org/10.5902/1984686X24631

ARAÚJO, J. C. Os gêneros digitais e os desafios de alfabetizar letrando. Trabalhos em Linguística Aplicada, Campinas, v.46, n.1, p. 79-92, 2007.

BARRIO, J.A. Evaluation del desarrollo psicoling stico em los ninos con sindrome de Down en edad escolar. In: FLÓREZ, J.; TRONCOSO, M.V. (Orgs.). Sindrome de Down y education. Santander: Ediciones Científicas y Técnicas, 1997. p.153-181

BISSOTO, M. L. O desenvolvimento cognitivo e o processo de aprendizagem do portador de Síndrome de Down: revendo concepções e perceptivas educacionais. Ciências \& Cognição; Ano 02, v. 04, 2005.

BRASIL. Ministério da Educação. Cadernos de Formação - PNAIC. Brasília: MEC/SECAD, 2012.

BRITO, C.L.R.; et al. Habilidades de letramento após intervenção fonoaudiológica em crianças do $1^{\circ}$ ano do ensino fundamental. Revista da Sociedade Brasileira Fonoaudiologia, São Paulo, v.15, n.1, p. 88-95, 2010.

COENGA, R.; et al. Portadores de Síndrome de Down: as experiências de letramento na APAE. Revista Educação e Linguagem, v. 2, n. 1, 2008.

FEISTAUER, C. M. O letramento na Síndrome de Down: o papel da família e da escola. Porto Alegre, 2014

FEITOSA, R. M.; TRISTÃO, R. M. Linguagem na Síndrome de Down. Psicologia: teoria e pesquisa, Brasília, vol. 14, n. 2, pp.121-126, 1998.

GIL, A.C. Como elaborar projetos de pesquisa. 4.ed. Sâo Paulo: Atlas, 2002.

KLEIMAN, A. B. É preciso "ensinar" letramento? Não basta ensinar a ler e escrever? Cefiel/IEL/Unicamp, 2005.

KOZMA, C. O que é síndrome de Down. In: STRAY-GUNDERSEN, K (Org). Crianças com síndrome de Down: guia para pais e educadores. Traduzido por: Maria Regina Lucena Borges-Osório. 2. ed. Porto Alegre: Artmed, p. 15-38, 2007.

LIMA, I.L.B.; et al. Contributions of the institutional diagnosis for speech language pathology and audiology practice in schools. Revista Distúrbios da Comunicação, São Paulo, v.27, n.2, p.213-223, 2015.

LIMA, I.L.B.; DELGADO, I.C.; CAVALCANTE, M. C. B. . Language development in Down syndrome: literature analysis. Revista Disturbios Da Comunicação, v. 29, p. 354-364, 2017.

LIMONGI, S.C.O. Linguagem na síndrome de Down. In: FERREIRA, L.P.; BEFI-LOPES, D.M.; LIMONGI, S.C.O. (Org). Tratado de Fonoaudiologia. São Paulo: Roca, p. 373-380, 2004.

MEDEIROS, N. A. Os jogos de linguagem no discurso infantil: implicações na constituição do letramento oral. Revista Brasileira de Linguística Aplicada, Belo Horizonte, v. 12, n. 4, p. 747-762, 2012. 
http://dx.doi.org/10.5902/1984686X24631

RANGEL, D. I.; RIBAS, L. P. Características da linguagem na síndrome de Down: implicações para comunicação. Revista Conhecimento Online, v. 2, n. 4, p. 18-29, 2011.

RIBEIRO, N.; SOUZA, L. A. P. Efeitos do(s) letramento(s) na constituição social do sujeito: considerações fonoaudiológicas. Revista CEFAC, São Paulo, v.14, p. 808-815, 2012.

SATO, D, T. B.; MAGALHÃES, I.; BATISTA JÚNIOR, J. R. L. Desdobramentos recentes da educação inclusiva no Brasil: discursos e práticas de letramento. RBLA, Belo Horizonte, v. 12, n. 4, p. 699-724, 2012.

SCHNEIDER, A. C. B.; SOUZA A. P. R.; DEUSCHLE, V. P. Intervenção Fonoaudiológica com gêneros textuais em um grupo de escolares. Rev. CEFAC. v. 12. n. 2. p. 337-345, 2010.

SIGNOR, R. O gênero sinopse como proposta de ação fonoaudiológica voltada para o desenvolvimento de competências em leitura e escrita. Revista Bakhtiniana, São Paulo, v.7, p. 219-239, 2012.

SOARES, M. Letramento e alfabetização: as muitas facetas. Revista Brasileira de Educação. n. 25. p. 5-17, 2004.

SOARES, M. Letramento: um tema em três gêneros. 3.ed. Belo Horizonte: Autêntica Editora, 2009.

TERRA, M. R. Letramento \& Letramentos: uma perspectiva sociocultural dos usos da escrita.

D.E.L.T.A., v.29, n.1, p. 29-58, 2013.

\section{Correspondência}

Isabelle Cahino Delgado - Universidade Federal da Paraíba Campus I - Lot. Cidade Universitária. CEP: 36307-352, João Pessoa, Paraíba, Brasil.

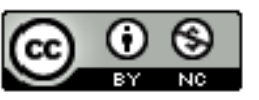

This work is licensed under a Creative Commons Attribution-NonCommercial 4.0 International (CC BY-NC 4.0) 